\title{
Práticas de Sustentabilidade Adotadas por Profissionais de Secretariado Executivo nas Organizações
}

\section{Sustainability Practices Used by Executive Secretaries Professionals at the Enterprises}

Cibelle da Silva Santiago ${ }^{1}$, Fernanda Cristina Sanches-Canevesi ${ }^{2}$ e Thays Lyanny da Cunha Garcia da Rocha ${ }^{3}$

${ }^{1}$ Universidade Federal da Paraíba, UFPB

${ }^{2}$ Universidade Estadual de Maringá, UEM

${ }^{3}$ Universidade Federal do Ceará, UFC 


\title{
Resumo
}

As discussões que envolvem o contexto da sustentabilidade socioambiental têm sido bastante presentes na atualidade. Dessa forma, o objetivo geral desta pesquisa é identificar de que maneira o profissional de Secretariado Executivo pode contribuir para implantação de medidas socioambientais nas organizações. A realização do estudo se justifica tendo em vista a importância de endossar no perfil do Secretário atitudes e competências que estejam ligadas à sustentabilidade organizacional. Assim, compreende-se que o profissional de secretariado precisa se vislumbrar como um agente colaborador para a implantação ou manutenção de medidas socioambientais. Desse modo, a metodologia utilizada foi a pesquisa bibliográfica, exploratória, sob uma abordagem qualitativa. O instrumento para a coleta de dados foi o questionário online aplicado por meio das redes sociais e os dados foram descritos por meio da Análise de Conteúdo. Como principais resultados, aponta-se que os Secretários têm colaborado para uma gestão empresarial mais sustentável a partir das seguintes práticas: economia de recursos papel, energia, água, cartuchos de impressora, materiais, reciclagem/reutilização de papel/ jornal/sacolas, adoção de um copo/garrafa para evitar os descartáveis e, por fim, a separação de resíduos alimentares de embalagens/coleta seletiva.

Palavras-chave: responsabilidade socioambiental, secretário executivo, ações sustentáveis

\begin{abstract}
Discussions involving the context of socioenvironmental sustainability have been currently observed nowadays. Therefore, the general purpose of this research is to identify how the Executive Secretariat professional can contribute to the implementation of social and environmental measures in organizations. This study is justified due to the importance of endorsing the attitudes and skills that are related to organizational sustainability in the profile of the Secretary. Thus, the professional secretariat needs to see himself as a collaborating agent for the implementation of socioenvironmental measures maintenance. The methodology used was bibliographic and exploratory research, under a qualitative approach. The instrument for data collection was the online questionnaire, applied through social networks and described through content analysis. As main results, the study shows that Secretaries have collaborated for a more sustainable business management based on the following practices: using less paper, energy, water, printer cartridges, materials, recycling/reusing paper/newspaper/bags, adoption of a glass/bottle to avoid disposables, and the separation of organic waste from packaging/selective collection.
\end{abstract}


Em um cenário de crescente globalização e expansão do conhecimento, as empresas, constantemente, buscam por diferenciais que as mantenham no mercado. Nesse contexto, os consumidores se tornam mais exigentes por produtos de qualidade e busca, por empresas que visam não somente o lucro, mas um compromisso com a sociedade e meio ambiente. O valor de uma empresa não depende apenas do seu resultado financeiro ao término de cada atividade, mas de vários aspectos particulares que determinam o seu reconhecimento no mercado (Pimenta, 2010). Neste sentido, as organizações comprometidas com uma gestão sustentável se destacam no meio corporativo. O compromisso assumido pelas organizações sustentáveis é de "produzir e fornecer produtos ou serviços que não causem impacto impróprio sobre o meio ambiente, utilizando-o de forma segura, apresentando melhores rendimentos no consumo de energia e recursos naturais, sendo recicláveis e reutilizando-se" (Dias, 2011, p. 100).

Ainda de acordo com o Dias (2011, p. 63), as organizações tornam-se ambientalmente sustentáveis quando demonstram engajamento no "modo de ver e fazer as coisas". Ou seja, quando sabem identificar o momento propício de mudar, pois percebem que as atualizações são indispensáveis e que, ao aderir a novos paradigmas, estão se adequando às exigências do mercado globalizado, além de acreditarem e difundirem um panorama sustentável. Dessa maneira, passam a contribuir com as necessidades emergentes, mas desenvolvendo uma produção com a mente e atitudes voltadas às questões socioambientais.

A inserção de práticas sustentáveis nos processos organizacionais gera benefícios às empresas e ao meio ambiente. Contudo, é mister afirmar que, para atingir os objetivos organizacionais, os funcionários são peças fundamentais, pois são eles que contribuem diretamente com a mão de obra e o sucesso da organização. E, para tanto, uma empresa sustentável deve investir na contratação de gestores sustentáveis entendem que "as pessoas produzem mais quando estão satisfeitas e envolvidas com o trabalho" (Carvalho, 2014, p. 2), que tenham, também, um olhar sobre a qualidade de vida de seus funcionários, para "desenvolver e qualificar os profissionais, trabalhando suas habilidades e competências" (Carvalho, 2014, p. 4).

Nesse contexto, a realização dessa pesquisa justifica-se a partir de necessidade de endossar no perfil do Secretário atitudes e competências que estejam ligadas à responsabilidade socioambiental das organizações. Isso pois, é interessante que o profissional de Secretariado visualize a implantação ou manutenção de medidas socioambientais, como parte de sua função. Para isso, é imprescindível que ele: a) conheça os conceitos e valores que permeiam a responsabilidade socioambiental empresarial; b) se descubra como parte do meio ambiente, no qual suas atividades laborais contribuem positiva ou negativamente para a sustentabilidade do ambiente em que vive. Tendo em vista essa necessidade, questiona-se: de que forma o profissional de Secretariado pode contribuir para a implantação de medidas socioambientais nas organizações, e assim, contribuir com a sustentabilidade?

De modo a responder à questão de pesquisa, este estudo objetivou identificar de que maneira o profissional de Secretariado Executivo pode contribuir para implantação de medidas socioambientais nas organizações. Para tal, delineou-se os seguintes objetivos específicos: a) apresentar as medidas socioambientais que são adotadas pelas organizações em que os Secretários atuam; b) descrever as atitudes sustentáveis desenvolvidas 
pelo profissional de Secretariado Executivo que estão em consonância com a sustentabilidade socioambiental empresarial; c) analisar o quanto os profissionais de secretariado estão envolvidos e comprometidos com a sustentabilidade nas organizações em que atuam.

É importante destacar que essa temática ainda tem sido pouca explorada na profissão de Secretariado, resvalando o motivo pelo qual as autoras se dispuseram a aprofundar os conhecimentos teóricos, aliados ao exercício dos profissionais que atuam em empresas com responsabilidade socioambiental. Além disso, a realização desse estudo justifica-se haja vista a necessidade da contribuição científica para a profissão de Secretariado por meio da pesquisa, que permite maior interação da universidade com as temáticas que estão em evidências no mercado de trabalho. Portanto, é preciso investigar como se dá a participação do profissional frente a esse tema, emergente na cultura das empresas, de maneira que as ações sustentáveis devem ser estendidas a todos os níveis hierárquicos (tático, estratégico e operacional), sobretudo, incorporadas ao fazer secretarial no dia a dia.

Para realização da pesquisa, a metodologia utilizada foi a pesquisa bibliográfica, exploratória, sob uma abordagem qualitativa. No que se refere à coleta de dados, utilizou-se o questionário hospedado nos formulários online do Google Docs, o qual foi aplicado através das redes sociais Facebook e WhatsApp para profissionais de diversas regiões do Brasil e, logo após, partiu-se para a análise dos dados sob o método de análise de conteúdo. Buscando explanar os resultados obtidos, esta pesquisa estruturou-se em quatro etapas: i) o referencial teórico; ii) procedimentos metodológicos; iii) análise dos resultados; e iv) considerações finais, seguidos das referências.

\section{Referencial Teórico}

\section{Sustentabilidade Socioambiental: Conceitos e Aplicabilidade nas Organizações}

Antes de tratar do conceito da sustentabilidade socioambiental, é necessário entender em que contexto essa temática emergiu. Barbieri e Cajazeira (2012), afirmam que o desenvolvimento sustentável (DS) emergiu a partir de um momento em que se notou que a capacidade de carga do planeta Terra não poderia ser ultrapassada sem que ocorressem grandes catástrofes sociais e ambientais. "Mas ainda, já há sinais evidentes de que, em muitos casos, os limites aceitáveis foram ultrapassados" (Barbieri, \& Cajazeira, 2012, p. 67).

No âmbito organizacional, o desenvolvimento sustentável está relacionado à forma como se praticam os negócios, de maneira a permitir que os meios ambientais ou sociais não se esgotem futuramente. A sustentabilidade relacionada aos negócios, segundo Savitz e Weber (2007), se trata da "gestão do negócio de maneira a promover o crescimento e gerar lucro, reconhecendo e facilitando a realização das aspirações econômicas e não econômicas das pessoas de quem a empresa depende, dentro e fora da organização" (Savitz, \& Weber, 2007, p. 3). As organizações, constantemente, buscam por diferenciais que as mantenham no mercado e, com a crescente globalização e expansão do conhecimento, os consumidores estão cada vez mais exigentes por produtos de qualidade e por empresas que visam não somente o lucro, mas um compromisso social e ambiente que alcance a sociedade, ou seja, promovendo a consciência da sustentabilidade socioambiental do negócio (Elkington, 2001). 
Corroborando com Ashley (2005), Karkotli (2006, p. 13) já afirmava que as organizações "estão inseridas em uma alarmante situação de desconformidade em relação ao meio ambiente, aos direitos humanos e às condições de trabalho; isto vem requerendo inciativas urgentes no sentido de amenizar essas deficiências". Além disso, a maior facilidade nas comunicações, devido à globalização, faz com que os consumidores e concorrentes fiquem atentos às práticas das empresas, criando um ambiente competitivo e propício ao desenvolvimento da consciência da sustentabilidade socioambiental. "A adoção da dimensão socioambiental no processo de gestão do negócio envolve a discussão de múltiplos aspectos da organização e demanda uma visão integrada da empresa" (Borger, \& Kruglianskas, 2004, p. 2).

Consideravelmente, o DS é importante para a sociedade como um todo, pois envolve seus diferentes âmbitos: social, ambiental, econômico, cultural, dentre outros. O DS é "como um processo de transformação que ocorre de forma harmoniosa nas dimensões espacial, social, ambiental, cultural e econômica a partir do individual para o global" (Silva, 2006, p. 18). Nessa perspectiva, para Elkington (2001), o idealizador da ideia do Tripple Bottom Line (tripé da sustentabilidade), a sustentabilidade é o equilíbrio entre os pilares ambiental, econômico e social. O DS, portanto, é um objetivo a ser alcançado e a sustentabilidade é o processo para atingir tal desenvolvimento. Já há algum tempo, autores afirmavam que existiam diversos benefícios para empresas que adotassem o DS e a consciência socioambiental.

A sustentabilidade socioambiental tem se apresentado, nesse aspecto, como um grande desafio às organizações, pois elas precisam reformular a cadeia de produção levando em consideração, impactar o meio ambiente o menos possível. Com isso, algumas organizações passaram a assumir uma responsabilidade frente às questões sociais e ambientais. Sobre isso, Dias (2011, p. 173) define responsabilidade social empresarial como sendo um "comportamento empresarial que integra elementos sociais e ambientais que não necessariamente estão contidos na legislação, mas que atendem às expectativas da sociedade em relação à empresa". Nesse sentido, as organizações que possuem responsabilidade socioambiental apresentam, minimamente, uma postura que relaciona estratégias organizacionais que beneficiam a sociedade em que está inserida, incluindo os stakeholders, além de diminuir o impacto ambiental causado por sua atividade.

Uma empresa que incorpora a sustentabilidade socioambiental à sua gestão pode se diferenciar das demais em seu segmento, conquistando, assim, mais clientes e fidelizando sua marca. Para Estigara, Pereira e Lewis (2009), a atuação de uma empresa em conformidade com a sustentabilidade socioambiental, proporciona diversos benefícios, dentre eles o amadurecimento no que tange às suas estratégias de manutenção e crescimento; e criação de uma política permanente para a empresa: as ações socioambientais são permanentes, planejadas, estratégicas e buscam a elevação da qualidade de vida e a inclusão social a médio e longo prazo, tornando-se assim, uma política permanente da empresa envolvendo sua estratégia.

Dessa forma, "negócios não têm a ver com fazer o máximo de dinheiro possível. Têm a ver com a criação de valor para as partes interessadas" (Mackey, \& Sisodia, 2013, p. 23). Para estes autores, as organizações devem, conscientemente, possuir um propósito que gere valor de forma equilibrada e sustentável para todos os 
stakeholders. Assim, o desafio da sustentabilidade socioambiental para as empresas atualmente consiste em fazer com que as organizações consigam se adaptar as novas exigências dos consumidores, passando a se responsabilizar por seus impactos no meio em que atuam e nos espaços públicos com os quais se relacionam. Corroboram Guevara e Dib (2007, p. 47), afirmando que "o grande desafio do século XXI será mudar o sistema de valores que está por trás da economia global, de modo que o torne compatível com as exigências da dignidade humana e da sustentabilidade ecológica".

Além de identificar os desafios das organizações, na visão de Ross e Tomlinson (2011), as pessoas em seu dia a dia também podem adotar comportamentos que promovam a sustentabilidade, inclusive no âmbito do seu ambiente de trabalho como, por exemplo, consumir produtos reciclados, substituir lâmpadas tradicionais pelas de LED, reduzir desperdícios, destinar corretamente os resíduos, dentre outras ações. Apesar dos benefícios existirem a partir da adoção da sustentabilidade socioambiental nos negócios, é preciso atentar-se para a forma como são desenvolvidas essas práticas, para que gerem impactos positivos e não o inverso, como o que ocorre com as propagadas verdes enganosas, mais conhecidas como greenwashing. $\mathrm{O}$ tópico seguinte aborda com maior propriedade as práticas socioambientais implantadas nas organizações.

\section{Práticas Socioambientais Adotadas pelas Organizações}

A gestão organizacional se constitui das "diferentes atividades administrativas e operacionais executadas pelas empresas para abordar os problemas ambientais decorrentes da sua atuação, buscando evitar que eles ocorram no futuro" (Barbieri, 2004, p. 137). Os problemas socioambientais gerados pelas organizações podem ser complexos, de maneira que a solução deve ser buscada pelos stakeholders envolvidos nesse processo. Todavia, a busca pela conscientização e incorporação de práticas socioambientais nas organizações não é fácil, pois demanda, principalmente, que as demais pessoas envolvidas estejam engajadas e comprometidas, além de dispor de conhecimento técnico sobre a causa e efeito dos impactos ambientais.

Dias (2011) apresenta dois tipos de empresas com base nos seus comportamentos em prol da adesão das práticas socioambientais: reativas e proativas. As atitudes reativas são de organizações que reagem a algum tipo de pressão ou demanda social, normativa e legislativa, procurando, por fim, obter alguma vantagem no processo de mudança a que estão sendo obrigadas a assumirem a causa ambiental. Já as organizações com atitudes proativas aderem e incorporam gestão, práticas e atitudes socioambientais independente das demandas e exigências sociais e ambientais, pois se debruçam a buscar soluções para problemas ocasionados pela própria atividade organizacional ou de outrem.

De acordo com Tachizawa e Bernardes (2008), as principais estratégias adotadas pela gestão ambiental nas organizações são: redução no custo e uso de energia e água; mudança na fabricação das embalagens; redução no uso de matérias-primas; reciclagem de sucatas, resíduos ou refugos; disposição adequada dos resíduos sólidos e lixo industrial; controle ou recuperação de emissões gasosas e líquidas; seleção de fornecedores ambientalmente corretos; investimento no sistema de controle e auditoria ambiental; investimento em rotulagem ambiental; 
projetos sociais em meio ambiente, educação, saúde, cultura, apoio à criança e ao adolescente; e projetos sociais em voluntariado.

Dias (2011) elenca alguns comportamentos e políticas proativas que as organizações podem aderir: - Implementar um sistema de gestão ambiental; - Proceder a modificações no processo produtivo, substituindo os produtos tóxicos ou nocivos por outros menos prejudiciais; - Estabelecer um programa de redução de emissões poluentes; -Estabelecer programas de formação e informação ambiental para o quadro de pessoal da organização; - Elaborar códigos de conduta de respeito ao meio ambiente - Criar um setor responsável, prioritariamente, com a questão ambiental - Participar ativamente das campanhas educativas e de prevenção organizadas pelos governos em todos os níveis (municipal, estadual e nacional), e daquelas promovidas pelas entidades representativas do seu setor produtivo; - Recuperar e reciclar os seus produtos e subprodutos; - Promover e incentivar a pesquisa de novas tecnologias e novos produtos que não prejudiquem o meio ambiente; - Diminuir o consumo de matérias-primas, água e energia; Diminuir a produção de resíduos (p. 176).

Ainda nesse contexto, conforme Tenório (2006), as organizações devem desenvolver suas ações práticas no contexto socioambiental alinhadas com sua cultura, como o desenvolvimento de programas de voluntariado, adoção de inciativas de marketing social, apoiando o desenvolvimento da comunidade ao seu redor, contribuindo com o debate sobre políticas públicas, colaborando com o desenvolvimento de políticas fiscais, educacionais, produtivas, ambientais, dentre outras, patrocínio de atividades culturais, fomentando assim o desenvolvimento sustentável.

Para Oliveira (2008), existem ainda outras formas práticas na qual as organizações também podem contribuir com a sustentabilidade socioambiental, utilizando o Investimento Social Privado, das Leis de Incentivos Fiscais que direcionam parte do imposto para patrocínio a projetos socioambientais, através da publicação de Relatórios de Sustentabilidade ou Balanço Social, adoção de pactos e iniciativas globais como o Pacto Global que dá diretrizes para as empresas dentro da temática social e ambiental e ainda através de normas e certificações.

Em virtude da diversidade de atitudes e práticas socioambientais, entende-se que ainda existem várias outras que devem ser exploradas e implementadas pelas organizações a fim de preservar o meio ambiente, buscar envolver e conscientizar os funcionários, engajar a sociedade por meio de programas e ações extensionistas para alcançar objetivos maiores. Com isso, é fundamental que as empresas criem consciência para a Sustentabilidade, refletindo através de suas ações práticas seu posicionamento e diminuindo seu impacto no meio em que atuam. Além disso, é importante que cada profissional que compõe a organização tenha noção de que sua atuação deve estar em sinergia com os princípios da sustentabilidade socioambiental.

A seguir, trata-se da importância e relação da atuação do profissional de Secretariado junto a sustentabilidade empresarial. 


\section{O Secretário Executivo e a Sustentabilidade Empresarial}

As diversas alterações no mercado, intensificadas a partir da revolução industrial, estabeleceram novos padrões de consumo da população. Isso, atrelado ao aumento populacional, motivou o surgimento da preocupação com a preservação do meio ambiente para as futuras gerações, como já citado neste referencial. Nesse cenário, foi necessário repensar as estratégias políticas, técnicas e econômicas para a sustentabilidade socioambiental e elaborar formas de redução dos impactos das organizações ao meio ambiente (Leff, 2003).

Assim, as organizações e governo foram se adaptando às mudanças ocorridas e impostas pelo sistema de mercado e a sustentabilidade passou a ser vista como um compromisso empresarial com o desenvolvimento sustentável. A partir dessa percepção, essas instituições passaram a desenvolver "ações, programas, projetos e estratégias voltadas para a sustentabilidade do seu negócio" (Guedes, \& Scherer, 2012, p. 7). Destarte, Dias (2011) afirma que a prática sustentável nas organizações é definida por um comportamento que integra elementos ambientais e sociais, que atendem às expectativas da sociedade. Contudo, para a execução dessas mudanças, é necessário que o capital humano se adeque às novas configurações do mercado. Deste modo, as organizações passaram a demandar um profissional diferenciado, preparado e capaz de enfrentar as incertezas e necessidades empresariais, de maneira a responder de forma assertiva às transformações econômicas (Santos, \& Moretto, 2011).

Essas alterações exigem dos profissionais capacidade de adaptação, em que Minarelli (1995, p. 22) já afirmava: "o mercado de trabalho valoriza e dá preferência a profissionais com múltiplas habilidades e com iniciativas". Nesse contexto, demanda-se de colaboradores que possuam habilidades múltiplas; abertos às mudanças; capazes de assumir riscos; ágeis; e flexíveis (Helal, 2005).

Por meio das características exigidas pelo mercado, pode-se dizer que o profissional de secretariado executivo se insere nesse cenário, visto que apresenta habilidades proativas, possui acesso aos processos organizacionais, às informações estratégicas e está junto aos centros decisórios das organizações. Diante disso, deve se tornar um agente facilitador nas relações interpessoais, na implantação de mudanças e ainda, deve atuar diretamente no fluxo de informações, de maneira a buscar melhorias no processo de comunicação.

Cumpre destacar que a profissão de secretariado executivo foi regulamentada no ano de 1985, a partir da promulgação da Lei no 7377 , de 30 de setembro do mesmo ano, que descreve a formação e atribuições do profissional ( Lei no 7377, 1985). Com o passar dos anos e aumento das exigências organizacionais, o profissional de secretariado tornou-se mais responsável pelos assuntos da empresa, passou a coordenar e administrar custos, supervisionar grupos de trabalho, recebeu autonomia e tornou-se metacompetente. Conforme afirmaram Bortolotto e Willers (2005), a essência da profissão exige o domínio de conhecimentos e habilidades em diversas áreas, tais como idiomas, relações humanas, finanças, economia, marketing, dentre outras.

Assim, a atuação do secretário executivo se modificou de forma significativa ao longo do tempo, resultando em uma evolução que acompanhou as alterações ocorridas no mercado de trabalho, conforme afirmam Neiva e D’Elia (2014, p. 15): “A profissão de Secretariado não só acompanhou, com mérito, a evolução gradativa da história como criou a sua própria". Dessa maneira, surgiram novos perfis profissionais para atender às novas condições 
mercadológicas, capazes de se adaptarem a comunicação, inovação tecnológica e com domínio transversal das relações humanas (Buenafuente \& Santos, 2010). Atrelado a essas características, observa-se que o profissional de secretariado executivo pode atuar diretamente como agente colaborador na sustentabilidade das organizações.

De acordo com Todorov (2013), o secretário executivo pode se tornar um viabilizador ideal e agente facilitador para o desenvolvimento de uma gestão empresarial eco responsável. Figueiredo (2014) acrescenta ainda que o profissional de secretariado executivo apresenta grande influência sobre as pessoas e a organização em que atua, deste modo, pode auxiliar a sustentabilidade da organização sugerindo medidas que envolvam a economia, proteção ao meio ambiente e ainda, realizando análises de custos e desperdício de energia e de materiais. Esses profissionais devem voltar sua atenção também para o que ocorre nas organizações e devem "pensar sempre de forma sustentável e contribuir para a diminuição dos impactos socioambientais pois (...) na maioria das organizações isto ainda não se transformou em práticas administrativas e operacionais efetivas" (Todorov, 2013, p. 370). Nesse aspecto, Buenafuente e Santos (2010) afirmam:

Ademais destas condições, o perfil do profissional para atuar no processo de gestão sustentável das corporações define-se por uma ampla condição de assessorar e ser assessorado, já que pode compreender a dinâmica do exercício de funções gerenciais, com sólido domínio de planejamento e controle (p. 11).

Em suma, é mister afirmar que as ações voltadas para a sustentabilidade, envolvem o desenvolvimento de atitudes que corroboram com as exigências de mercado. Por sua vez, essas ações demandam de um profissional que conduza esses processos sustentáveis, que se adeque as especificidades da organização, aberto a mudanças, com visão generalista e que possua capacidade de articulação. Nesse sentido, o secretário executivo deve utilizar de sua posição estratégica na organização para influenciar todos os níveis empresariais para a questão da sustentabilidade (Figueiredo, 2014).

Figueiredo (2014, p. 107), cita como exemplo de ações passíveis de serem realizadas pelo profissional de secretariado executivo atento "não só aos interesses da empresa como ao próprio planeta": deslocamento econômico; redução na utilização nos materiais de escritório; evitar desperdício de papel; desligar o que for desnecessário; demonstrar disposição para servir de exemplo aos demais.

Nesse paralelo, acompanhando as tendências do mercado, o secretário executivo foi, ao longo do tempo, atendendo às exigências impostas e alterando seu perfil. Todavia, as ações por ele realizadas devem também contribuir para com o desenvolvimento da sociedade, para tanto, é importante que esse profissional conheça o processo de desenvolvimento econômico, responsável por alicerçar as práticas sustentáveis nas organizações.

Considera-se, por fim, que os novos paradigmas da sustentabilidade socioambiental exigem profissionais qualificados e engajados com os ideais da organização e, que estejam aptos a enfrentar os desafios e oportunidades impostos pelas alterações de mercado. Nesse contexto, o profissional de Secretariado Executivo pode atuar como agente facilitador desse processo, tendo em vista suas habilidades na difusão dos processos organizacionais. 


\section{Metodologia}

Para a elaboração e alcance dos objetivos deste trabalho, foi necessário utilizar alguns procedimentos metodológicos que perfazem o caminho da pesquisa científica, sendo a pesquisa do tipo bibliográfica e exploratória. No que se referem aos procedimentos, a pesquisa é bibliográfica que, segundo Lakatos e Marconi (2009), aborda pesquisas publicadas anteriormente em periódicos científicos, anais de eventos e outros canais. Nesta pesquisa, as principais referências bibliográficas utilizadas basearam-se na sustentabilidade socioambiental, o perfil e a atuação do profissional de Secretariado Executivo.

Conforme Gil (2008) o estudo exploratório é caracterizado por explorar situações desconhecidas ou pouco exploradas. Já a abordagem é qualitativa costuma ser direcionada, ao longo de seu desenvolvimento e não busca enumerar ou medir eventos geralmente, não empregando instrumental estatístico para análise dos dados.

O Instrumento de coleta de dados utilizado foi o questionário misto elaborado na plataforma do Google Formulários, com perguntas fechadas e abertas. O questionário sendo aplicado através de ferramentas digitais permitiu alcançar vários secretários, em diversos estados brasileiros. Dessa forma, foi divulgado nas redes sociais, especificamente em grupos que reúnem secretários de várias regiões do País, objetivando identificar os profissionais que atuam em empresas com responsabilidade socioambiental, os quais são os sujeitos da pesquisa de campo. A pesquisa foi aplicada no período de 10 a 25 de maio de 2017, e a amostra final foi composta por 97 questionários completos e válidos. $O$ intuito foi coletar respostas dos secretários que, atualmente, estão trabalhando/estagiando a fim de identificar como o profissional de Secretariado Executivo pode contribuir para implantação de medidas socioambientais na organização em que trabalha.

Para a análise de dados foi utilizado o método de análise de conteúdo que, para Bardin (2006, p. 38), consiste em "um conjunto de técnicas de análise das comunicações, que utiliza procedimentos sistemáticos e objetivos de descrição do conteúdo das mensagens".

\section{Análise e discussão dos resultados}

O problema de pesquisa investigado nesse estudo, procurou identificar quais as maneiras que o profissional de secretariado pode contribuir na implantação de medidas socioambientais na organização em que atua. Para tanto, traçou-se inicialmente o perfil dos profissionais que participaram da pesquisa: $89 \%$ dos respondentes são do sexo feminino e da totalidade dos profissionais, $62 \%$ atuam na região Nordeste do País. Os demais respondentes atuam em empresas de todas as regiões do País, sendo: 15\% na região Norte, $11 \%$ na região Sul, $9 \%$ na região Sudeste e $3 \%$ na região Centro-Oeste. Ainda no que se refere ao perfil dos respondentes, constatou-se que 33\% dos profissionais atuam em organizações do setor público, 30\% no setor privado e 2\% em ONGs (Organizações Não Governamentais). Além disso, acerca do tamanho dessas organizações, 56\% trabalham em empresas de grande porte, $9 \%$ de médio porte e $35 \%$ em empresas de pequeno porte.

Buscando atender ao objetivo central de estudo, de identificar como o profissional de secretariado executivo pode contribuir para implantação de medidas socioambientais na empresa em que trabalha, foram elaboradas algumas questões que permitissem às pesquisadoras esse entendimento. 
Após traçar o perfil dos respondentes, Ihes foi indagado se acreditam que o profissional de Secretariado pode auxiliar no desenvolvimento da sustentabilidade organizacional. O resultado obtido considera-se satisfatório, tendo em vista que $93 \%$ afirmaram que sim, o profissional pode auxiliar no desenvolvimento de ações e $9 \%$ afirmaram que talvez possa e 1\% acredita que não pode. A fim de aprofundar a temática, solicitou-se aos que sinalizaram positivamente, que justificassem a resposta dada. Vale destacar que nessa questão, poderia ser escolhida mais de uma alternativa como resposta. As alternativas elencadas encontram-se na Figura 1:

\section{Figura 1}

O profissional de Secretariado pode auxiliar no desenvolvimento da sustentabilidade organizacional

\begin{tabular}{|c|c|c|}
\hline Área & Justificativa & Percentual \\
\hline \multirow[t]{10}{*}{ Atuação profissional } & É um profissional competente e que se preocupa com sustentabilidade e lida & $28 \%$ \\
\hline & com materiais que podem ser reciclados / reutilizados, reduzindo o uso de & \\
\hline & papel / reduzindo o tempo de aparelhos ligados / redução de energia / água e & \\
\hline & desperdício de um modo geral / Cogerindo e organizando coleta seletiva e no & \\
\hline & incentivo a reciclagens e menos contaminação ambiental / alvarás e licenças, já & \\
\hline & é solicitado alguns requisitos de sustentabilidade / divulgando normas do tema & \\
\hline & O profissional em Secretariado Executivo pode organizar e gerir ações de & $24 \%$ \\
\hline & sustentabilidade/implantação de projetos & \\
\hline & Através de pesquisas e divulgação na organização & $11 \%$ \\
\hline & Através da implementação no seu cotidiano & $8 \%$ \\
\hline \multirow[t]{2}{*}{ Influência profissional } & Como agente facilitando / Incentivando os colegas/equipe de trabalho & $28 \%$ \\
\hline & Pode contribui por ocupar posição estratégica e liderar equipes & $11 \%$ \\
\hline \multirow[t]{4}{*}{ Formação profissional } & Por colaborar por possuir competências necessárias e perfil para auxiliar e & $17 \%$ \\
\hline & acompanhar o desenvolvimento de ações de sustentabilidade organizacional. & \\
\hline & Por possuir visão holística e abrangente da organização & $11 \%$ \\
\hline & Pela criatividade ou força de vontade pode auxiliar & $8 \%$ \\
\hline
\end{tabular}

Nota. dados da pesquisa (2017).

Para formulação da Figura 1 foram elencadas as respostas dos profissionais em grupos a fim de facilitar a análise. Destaca-se que 93 respondentes deixaram em branco, então os percentuais foram calculados mediante os que responderam. Percebe-se que as justificativas citadas pelos respondentes para confirmar que de fato o profissional de Secretariado é capaz de contribuir para a sustentabilidade socioambiental de uma organização estão centrados em três âmbitos. No primeiro, em que foram citadas ações relativas à sua atuação profissional, $28 \%$ dos secretários afirmaram que podem contribuir com ações práticas de seu cotidiano na utilização de materiais que podem ser reciclados / reutilizados, reduzindo o uso de papel / reduzindo o tempo de aparelhos ligados / redução de energia / água e desperdício de um modo geral, dentre outras que podem ser observadas na Figura 1.

Em segundo, no âmbito da forma como o profissional de Secretariado influencia os demais colegas de trabalho, $28 \%$ afirmaram que contribuem como agente facilitador, incentivando os colegas/equipe de trabalho a terem uma postura mais sustentável e, $11 \%$ alegaram que podem contribuir mais enfaticamente ao ocupar 
uma posição estratégica junto aos gestores, além de liderar equipes desempenhando uma liderança pela sustentabilidade.

Os profissionais que desempenham uma liderança pela sustentabilidade são flexíveis, preocupam-se com o meio em que estão inseridos, acreditam que é possível buscar uma conciliação entre ganho financeiro sem agredir tanto ao meio ambiente. Por isso, eles têm pensamento estratégico, raciocinam de forma interligada, procuram alinhar as necessidades atuais com as futuras, tomando como base resultados e experiências vivenciadas, além de possuírem visão sistêmica da organização (Silva, 2016, p. 32).

Por fim, em terceiro lugar, no âmbito da formação profissional, os respondentes justificaram a capacidade do secretário em contribuir com a Sustentabilidade afirmando aspectos relativos às competências necessárias e o perfil para auxiliar e acompanhar o desenvolvimento de ações de sustentabilidade organizacional (17\%). Tais resultados, estão em consonância com o que afirmam Buenafuente e Santos (2010) e Todorov (2013), que defendem que os secretários executivos possuem um perfil profissional facilitador nos processos de gestão sustentável. Sobre isto, 11 \% informaram que os secretários devem possuir visão holística e abrangente da organização, além da criatividade ou força de vontade para auxiliar os gestores (8\%)

Adiante, o questionário indagou-se se eles adotavam práticas sustentáveis no seu local de trabalho, a maioria dos respondentes, $77 \%$ afirmou que sim, outros $15 \%$ disseram que talvez adotem alguma prática e, apenas $8 \%$, afirmaram que não adotam nenhuma prática. Mesmo que a temática da sustentabilidade ainda seja pouca difundida no meio Secretarial, vê-se esse resultado de forma otimista, pois a grande maioria dos respondentes adotam, minimamente, alguma prática sustentável no seu local de trabalho. Como forma de justificar esse cenário foi solicitado aos profissionais que exemplificassem essas ações práticas, a partir das quais foi possível construir a Figura 2:

\section{Figura 2}

Ações práticas desempenhadas pelos profissionais de Secretariado que contribuem para a Sustentabilidade Socioambiental

\begin{tabular}{ll}
\hline \multicolumn{1}{c}{ Ações } & Percentual \\
\hline Economia de recursos (papel, energia, água, cartuchos impressora, materiais) & $55 \%$ \\
Reciclagem/reutilização de papel/jornal/sacolas & $35 \%$ \\
Adoção de um copo/garrafa para evitar os descartáveis & $31 \%$ \\
Separação de resíduos alimentares de embalagens/coleta seletiva & $20 \%$ \\
Participando de Programa de Voluntariado & $14 \%$ \\
Estímulo à solidariedade/doação & $2 \%$ \\
Conscientização sobre as importâncias das práticas sustentáveis & $2 \%$ \\
Utilização de material eletrônico até o fim da vida útil & $1 \%$ \\
Usando minimamente produtos que agridem o meio ambiente & $1 \%$ \\
Estimulo a utilização de certificações digitais em eventos, em datas comemorativas & $1 \%$ \\
8s & $1 \%$ \\
Colaboração com os Projetos Sociais & $1 \%$ \\
\hline
\end{tabular}


Os resultados refletidos na Figura 2, estão diretamente relacionados ao que afirma Figueiredo (2014), quando se refere às ações voltadas à sustentabilidade e que podem ser executadas pelo secretário executivo à exemplo da economia de recursos. Com isso, a ação que é mais desenvolvida pelos profissionais para contribuir com a Sustentabilidade da organização em que atuam é a economia de recursos físicos e naturais (papel, cartuchos, impressora, materiais de escritório, energia e água,) representados por $55 \%$ das respostas. Em seguida as ações mais citadas foram a reciclagem/reutilização de papel/jornal/sacolas (35\%), a adoção de um copo/garrafa para evitar os descartáveis (31\%) e a separação de resíduos alimentares de embalagens/coleta seletiva (20\%). Questionou-se, também, aos participantes, se eles adotavam práticas socioambientais fora da organização, onde $90 \%$ afirmaram que sim, $8 \%$ afirmaram que talvez e apenas $2 \%$ disseram que não. Nesse contexto percebe-se algumas ações destacadas por Figueiredo (2014) no referencial teórico como redução na utilização nos materiais de escritório, cuidado ao evitar desperdício de papel a economia de energia ao desligar o que for desnecessário a própria disposição para servir de exemplo aos demais.

Esse cenário mostra-se positivo, tendo em vista que o profissional de Secretariado atua também na gestão administrativa da organização, sendo possível contribuir para que os recursos sejam utilizados de forma consciente desenvolvendo, assim, uma consciência para a Sustentabilidade. Além disso, conforme ressaltado por Ross e Tomlinson (2011) o desenvolvimento de ações que contribuem para a Sustentabilidade agregam, também, valor individual mesmo quando pratica ações sustentáveis no seu ambiente de trabalho.

Contudo, percebe-se ainda que a quantidade de ações citadas foi baixa, tendo em vista o amplo contexto da sustentabilidade socioambiental, conforme destacado por Borger e Kruglianskas (2004), o qual envolve múltiplos aspectos da organização e demanda uma visão integrada da empresa. O profissional de Secretariado apesar de ter uma visão holística da organização, atua ainda de forma tímida com relação a ações de Sustentabilidade.

A fim de verificar as medidas socioambientais adotadas pelas organizações em que os profissionais trabalham, elencou-se algumas opções, de forma que eles poderiam marcar mais de uma opção. Nesse sentido as informações selecionadas foram agrupadas na Figura 3:

Figura 3

Medidas socioambientais adotadas pelas organizações em que os secretários trabalham

Medidas

Percentual

I. A organização manifesta compromisso socioambiental em suas estratégias corporativas (Planejamento $41 \%$ estratégico, visão, missão etc.)

II. A organização trabalha com gerenciamento de resíduos. (Programa de Gerenciamento de Resíduos Sólidos, lixeiras para cada tipo de resíduo ou outro).

III. A organização já tentou reduzir seu impacto ambiental em termos de minimização e reciclagem de resíduos.

IV. A organização apoia o desenvolvimento de ações sociais mediante arrecadação de alimentos, produtos, 
V. A organização possui alguma política formal ou programa de responsabilidade empresarial que inclua

aspectos socioambientais.

VI. A organização promove cursos relacionados à responsabilidade social e ambiental para todos os funcionários.

VII. A organização incentiva e mobiliza o trabalho voluntário de seus funcionários em ONG's ou projetos sociais.

VIII. A organização disponibiliza informação ambiental clara e precisa sobre os seus produtos, serviços e atividades aos clientes, fornecedores, comunidade local etc.

IX. A organização na qual auto não desenvolve ações socioambientais

Nota. Dados da pesquisa (2017).

Dos 97 profissionais que afirmaram estar trabalhando, observa-se no quadro acima que o item I foi citado por 41\% deles e está relacionado ao compromisso da Sustentabilidade Socioambiental inserido na estratégia da organização corroborando com o que foi abordado por Estigara et al. (2009): a organização que incorpora a Sustentabilidade Socioambiental à sua gestão tem benefícios no que tange às suas estratégias de manutenção e crescimento, como a criação de política permanente para a empresa com ações socioambientais permanentes, planejadas, estratégicas que buscam a elevação da qualidade de vida e a inclusão social. Tais fatores destacados por Estigara et al. (2009) também podem ser observados no item V, em que 30\% participantes afirmaram que a organização possui política formal ou programa de responsabilidade empresarial que inclua aspectos socioambientais.

Outro aspecto que sobressaiu foi o item II que trata gerenciamento de resíduos (Programa de Gerenciamento de Resíduos Sólidos, lixeiras para cada tipo de resíduo ou outro), com 41\%. No item III, com 40\%, a redução do impacto ambiental em termos de minimização e reciclagem de resíduos, sendo uma ação realizada pela organização e diagnosticada como uma prática da sustentabilidade voltada para os impactos no Meio Ambiente, conforme as ações embasadas no referencial teórico por Dias (2011). Os itens (VI, VII), também constituem ações de cunho socioambiental, destacadas por Dias (2011) e que estão ligadas ao público interno da organização, aparecendo de forma de forma pontual e em menor quantidade. Esse cenário pode justificar de certa forma o quadro 2 acerca das ações socioambientais dos profissionais de Secretariado Executivo em suas organizações, em que foram citadas ações fundamentais, mas também me menor quantidade e variedade, podendo relacionar o pouco incentivo de suas organizações na conscientização e incentivo do público interno para o desenvolvimento de ações dessa temática.

Assim, depreende-se que é necessário que as organizações invistam mais em capacitação e incentivo a consciência socioambiental do seu público interno para que a Sustentabilidade possa acontecer em todas as dimensões do Tripé da Sustentabilidade, pois a gestão deve ser articulada com as pessoas de quem a empresa depende, dentro e fora da organização (Savitz \& Weber, 2007, p. 3). Destaca-se, ainda, 31\% dos respondentes afirmaram que suas organizações não desenvolviam diretamente ações socioambientais, fator preocupante, 
tendo em vista o contexto da Sustentabilidade destacado por Guevara e Dib (2007, p. 47), em que o desafio atual consiste em mudar o sistema de valores das organizações para com a sustentabilidade e Todorov (2013) acerca da capacidade do secretário em desenvolver ações.

Em continuidade, perguntou-se aos secretários em quais ações de sustentabilidade desenvolvidas e promovidas pela organização (Figura 3) eles se envolviam diretamente, $69 \%$ informou as ações que já haviam citado na Figura 2. Ou seja, as ações que alguns secretários respondentes desenvolvem são a partir das medidas implantadas pela organização. Nesse aspecto tem-se duas preposições: 1) o secretário se envolve com as medidas sustentáveis propostas pela organização deixando-se influenciar para assumir uma postura mais sustentável; 2) o secretário se limita a desempenhar as ações sustentáveis propostas pela organização, sem ter ousadia de sugerir/ implementar outras práticas. Isso se deve pela falta de conhecimento de outras práticas ou, infelizmente, pela falta de proatividade e compromisso com o meio ambiente, em buscar novas alternativas para promover um ambiente administrativo mais sustentável.

Por fim, foi questionado aos profissionais participantes da pesquisa sobre o grau de importância que eles dão a responsabilidade socioambiental das organizações, de acordo com os dados do Figura 4.

\title{
Figura 4
}

Grau de importância atribuída pelos profissionais de Secretariado à responsabilidade socioambiental das organizações

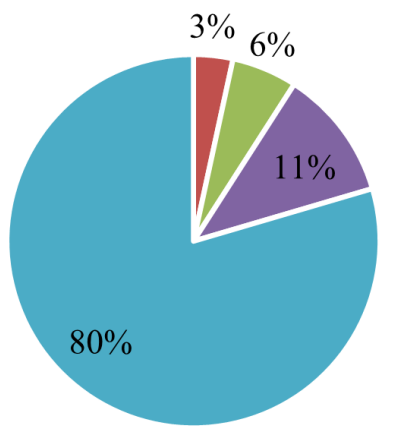

\author{
- Sem importância \\ - Pouco importante \\ - Importante \\ - Muito importante
}

Fonte: dados da pesquisa (2017).

Percebe-se que $80 \%$ dos profissionais respondentes dizem que a abordagem da responsabilidade socioambiental pelas organizações é de extrema importância. Por isso, é relevante que o profissional de Secretariado considere esta temática pertinente, asseverando e colaborando em desenvolver ações para a melhoria da sustentabilidade empresarial, seja no ambiente laboral ou extensionadas aos ambientes sociais. Sobre isso, Quadros e Tavares (2014) apontam que:

Diversos estudos apontam a sustentabilidade como peça fundamental da inovação. Reduzir a quantidade de matérias primas usadas na produção ou repensar processos para eliminar o impacto ambiental de certas substâncias traduzindo-se, cada vez mais, em melhoria nos indicadores financeiros da empresa. Em um futuro próximo, as empresas que não adotarem práticas sustentáveis não conseguirão mais competir no mercado (Quadros, \& Tavares, 2014, p. 46). 
Nesse cenário, concorda-se que é fundamental que as organizações busquem o desenvolvimento de ações voltadas à sustentabilidade para manterem-se competitivas no mercado, da mesma forma que o profissional de secretariado executivo deve atuar como agente facilitador e colaborador deste processo.

\section{Considerações Finais}

A crise ambiental passou a representar um fator limitante no crescimento econômico e populacional, a nível mundial. A partir dessas percepções, o termo desenvolvimento sustentável popularizou-se, determinando a necessidade de aplicação e elaboração de políticas públicas ambientais e sociais no sentido de mitigar a degradação ambiental. Com isso, as organizações passaram a buscar diferenciais que as mantivessem competitivas, pois o consumidor também passou a ser mais exigente, procurando produtos de qualidade e por organizações que apresentem um compromisso com a sociedade. Deste modo, algumas organizações foram se adaptando às mudanças impostas pelo sistema de mercado, quando então surgiu a percepção da necessidade de abranger e valorizar os recursos humanos, além de adotar processos voltados à sustentabilidade. Nesse aspecto, demandase colaboradores e stalkeholders comprometidos e engajados com as práticas voltadas à sustentabilidade na organização.

No que se refere ao desempenho da função do secretário executivo nessa questão, esse estudo identificou que tal profissional desempenha as competências necessárias para auxiliar às organizações no desenvolvimento de ações sustentáveis. Considera-se que o objetivo geral desse estudo foi atingido, visto que se identificou como o profissional de Secretariado Executivo tem contribuído para a implantação de medidas socioambientais na organização em que atua, a partir da economia de recursos; reciclagem e reutilização de materiais; separação e coleta seletiva, dentre outras. O desenvolvimento dessas ações agrega valor ao desenvolvimento sustentável.

Afirma-se, então, que esse resultado é satisfatório e está em consonância com o que afirmam publicações na área (Minarelli, 1995; Buenafuente \& Santos, 2010; Santos \& Moretto, 2011; Todorov, 2013; Figueiredo, 2014), visto que o profissional de secretariado executivo atua na gestão empresarial e apresenta características comportamentais que atendem às necessidades do perfil profissional adequado para atuar na sustentabilidade. Por meio disso, pode desenvolver uma consciência para a sustentabilidade na organização como um todo.

No entanto, entende-se que essa atuação poderia ocorrer de maneira mais abrangente, visto que os respondentes ainda atuam de forma tímida no que se refere a aplicação de ações de sustentabilidade no seu ambiente de trabalho. Para tanto, é necessário que as organizações realizem capacitações e busquem incentivar seus colaboradores, no sentido de desenvolver uma cultura de consciência socioambiental que contribua para que ocorra a sustentabilidade nos processos de gestão. Nessa perspectiva as empresas que querem se manter competitivas no mercado, necessitam adotar práticas sustentáveis. Contudo, esse estudo identificou que diversas organizações em que atuam os profissionais investigados, não desenvolvem diretamente ações socioambientais. Tal fator pode ser considerado limitante no desempenho das ações de sustentabilidade executadas pelos profissionais de secretariado executivo. Todavia, destaca-se, que os profissionais investigados consideram a responsabilidade socioambiental organizacional extremamente importante. 
Portanto, cumpre destacar que o secretário executivo desempenha um papel relevante no tocante às ações socioambientais e que, a partir de seu perfil profissional, está apto à auxiliar a organização em que atua, na aplicação e desenvolvimento dessas práticas, além de influenciar os colegas de trabalhos a absorverem novas posturas socioambientais. Para a sucessão deste estudo, sugere-se a realização de pesquisas futuras que investiguem a formação para a sustentabilidade desses profissionais, bem como compreender de que maneira ocorre o preparo teórico que sustenta suas ações na organização em que atua. 


\section{Referências}

Ashley, P. A. (2005). Ética e responsabilidade social nos negócios. (2a ed.). São Paulo: Saraiva.

Barbieri, J. C. (2004). Gestão ambiental empresarial: conceitos, modelos e instrumentos. São Paulo: Saraiva.

Barbieri, J. C. \& Cajazeira, J. E. R. (2012). Responsabilidade Social Empresarial e empresa sustentável: da teoria à prática. (2a ed.) São Paulo: Saraiva.

Bardin, L. (2006). Análise de conteúdo. Lisboa: Edições 70.

Bortolotto, M. F. P. \& Willers, E. M. (2005). Profissional de Secretariado Executivo Bilíngue: explanação das principais características que compõem o perfil. Revista Expectativa, 4(4), 45-56.

Borger, G. \& Kruglianskas, I. (2004). Corporate social responsibility and environmental and technological innovation performance: case studies of Brazilian Companies. International Journal of Technology, Policy and Management - Portugal, Special Issue - Topics: Systems and Policies Fostering Sustainanbility, 4(4).

Buenafuente, S. M. F. \& Santos, F. A. [dos]. (2010). Sustentabilidade corporativa e o profissional de Secretariado Executivo. In XVII Congresso Nacional de Secretariado. Fortaleza/CE. Recuperado de: http://www.fenassec. com.br/pdf/xxvii_oral_2_lugar.pdf

Carvalho, M. F.S [de]. (2014). Gestão de pessoas: implantando qualidade de vida no trabalho sustentável nas organizações. Revista Científica de ITPAC, Araguaína, 7 (1), 3-4, jan. Recuperado de: https://assets.unitpac. com.br/arquivos/Revista/71/6.pdf

Dias, R. (2011). Gestão ambiental: responsabilidade social e sustentabilidade. (2 ed.). São Paulo: Atlas.

Elkington, J. (2001). Canibais com garfo e faca. São Paulo: Makron Books.

Estigara, A., Pereira, R., \& Lewis, S. A. L. B. (2009). Responsabilidade Social e incentivos fiscais. São Paulo: Atlas.

Figueiredo, V. (2014). Universo Secretariado: dicas \& dogmas reavaliados. Multifoco: Rio de Janeiro.

Gil, A. C. (2008). Como elaborar projetos de pesquisa. (5a ed.). São Paulo: Atlas.

Guedes, E. P. \& Scherer, F. L. (2012). Práticas de inovação e sustentabilidade: estudo de caso em uma empresa de transporte rodoviário de passageiros. In 1 Fórum Internacional Ecoinovar, Santa Maria/RS. Recuperado de: http://ecoinovar.com.br/cd/artigos/ECO015.pdf

Helal, D. H. (2005). Flexibilização organizacional e empregabilidade individual: proposição de um modelo explicativo. Caderno EBAPE.BR, 3(1), 01-15. Recuperado de: http://bibliotecadigital.fgv.br/ojs/index.php/cadernosebape/ article/view/4906

Guevara, A. J. H. \& Dib, V. C. (2007). Da sociedade do conhecimento à sociedade da consciência. São Paulo: Saraiva.

Karkotli, G. (2006). Responsabilidade social empresarial. Rio de Janeiro: Vozes.

Lakatos, E. M. \& Marconi, M. A. (2009). Técnicas de pesquisa. (7 ed.). São Paulo: Atlas.

Leff, E. (2003). Pensar a complexidade ambiental. In: Leff, E. A complexidade ambiental (Coord.). São Paulo: Cortez.

Lei $n^{\circ}$ 7.377, de 30 de setembro de 1985 (1985). Dispõe sobre o Exercício da Profissão de Secretário e dá outras Providências. Brasil: Presidência da República. Recuperado de http://www.planalto.gov.br/ccivil_03/Leis/ L7377.htm 
Mackey, J. \& Sisodia, R. (2013). Capitalismo consciente. São Paulo: HSM.

Minarelli, J. A. (1995). Empregabilidade: o caminho das pedras. São Paulo: Gente.

Neiva, E. G. \& D’Elia, M. E. (2014). As novas competências do profissional de Secretariado. (3a ed.). São Paulo: IOB.

Oliveira, J. A. P. (2008). Empresas na sociedade: sustentabilidade e responsabilidade social. Rio de Janeiro: Elsevier.

Pimenta, H. C. D. (2010). Sustentabilidade empresarial: práticas em cadeias produtivas. IFRN Editora: Natal.

Quadros, R. \& Tavares, A. N. (2014). À conquista do futuro: sustentabilidade como base da inovação de pequenas empresas. Ideia Sustentável, 9(36), 30-31, jul. Recuperado de: https://issuu.com/caccibycassiostandt/docs/ is36

Ross, J. \& Tomlinson, B. (2011). Negabehaviors and Environmental Sustainability. Journal of Sustainability Education, 2, mar. Recuperado de: http://www.jsedimensions.org/wordpress/wp-content/uploads/2011/03/ RossTomlinson2011.pdf

Santos, M. E. [dos] \& Moretto, C. F. (2011). O mercado de trabalho do secretário executivo no contexto da dinâmica produtiva e do emprego recentes no Brasil. Secretariado em Revista, 7, p. 21-35. Recuperado de: http://seer. upf.br/index.php/ser/article/download/2324/1478/

Savitz, A. W. \& Weber, K. (2007). A Empresa Sustentável: o verdadeiro sucesso é o lucro com responsabilidade social e ambiental. Rio de Janeiro: Elsevier.

Silva, C. L. (2006). Desenvolvimento sustentável: um modelo analítico e adaptativo. Petrópolis - RJ: Vozes.

Silva, E. F. (2016). Gestão sustentável empresarial: as técnicas secretariais sob a ótica da sustentabilidade ambiental. (Trabalho de Conclusão de Curso, Universidade Federal da Paraíba, João Pessoa/PB).

Tachizawa, T. A. \& Bernardes, R. O. (2008). Gestão socioambiental: estratégias na nova era da sustentabilidade. Rio de Janeiro: Elsevier, 2008.

Todorov, N. (2013). O profissional de secretariado e a sustentabilidade. In: D’elia, B., Morim, M., \& Sita, M. Excelência em Secretariado. São Paulo: Ser Mais.

Tenório, F. G. (2006). Responsabilidade social empresarial: teoria e prática. (2a ed.). Rio de Janeiro: FGV, 2006. 